\title{
The role of left atrial enlargement and age in the prediction of recurrence in embolic strokes of undetermined source
}

\section{El papel del crecimiento auricular izquierdo y la edad como predictores de recurrencia en infarto cerebral embólicos de origen indeterminado}

\author{
Beatriz Mendez ${ }^{1,2}$, Cristina Ramos-Ventura², Carlos Zapata², Carmen Arteaga², \\ Eduardo Soriano-Navarro², Fernando Espinosa-Lira², Rodrigo González-Oscoy², Miguel Barboza², \\ Francisco-Javier Roldán ${ }^{4}$, and Antonio Arauz ${ }^{2 *}$ \\ ${ }^{1}$ Endovascular Stroke Therapy, National Institute of Neurology and Neurosurgery Manuel Velasco Suárez, Mexico City, Mexico; ${ }^{2}$ Stroke Clinic, \\ National Institute of Neurology and Neurosurgery Manuel Velasco Suárez, Mexico City, Mexico; ${ }^{3}$ Department of Neurology, School of Medicine, \\ University of Costa Rica, San José, Costa Rica; ${ }^{4}$ Ecocardiography Unit, National Institute of Cardiology Ignacio Chavez, Mexico City, Mexico
}

\begin{abstract}
Objectives: Left atrial disease is an independent risk factor for ischemic stroke and can be used to predict atrial fibrillation (AF). We examine whether left atrial enlargement (LAE) could predict stroke recurrence in patients with embolic stroke of undetermined source (ESUS). Materials and methods: Sixty-four patients with a confirmed diagnosis of ESUS were followed for a median of 22 months. Clinical data and echocardiogram findings were recorded. The echocardiogram interpretation was performed centrally and blindly. The Brown ESUS - AF score was used to categorize patients into high (human resource planning [HRP]: score > 2) and low-risk patients (non-HRP: score 0-1). Stroke recurrence was the primary outcome. Results: The median age was 62 years (range: 22-85 years); and 33 (51.6\%) were men. The median initial NIHSS score was three points (range: 0-27). Twelve (18.8\%) patients were categorized as HRP. We found a significant tendency toward recurrence among HRP versus non-HRP patients. Three (25\%) HRP versus $2(3.8 \%)$ non-HRP experienced recurrence (OR: $8.395 \% \mathrm{Cl}$ 1.2-57; $p=0.042$ ); this association was related to severe atrial dilatation (OR: $14.595 \% \mathrm{Cl}$ 0.78-277, $p=0.02$ ) and age > 75 years (OR: $12.795 \% \mathrm{Cl}$ 1.7-92.2, $p=0.03$ ). We found no differences in recurrence in a univariate analysis. Conclusions: Patients with severe $L A E$ who are 75 years old or older have a significant tendency to experience stroke recurrence.
\end{abstract}

Key words: Left atrial enlargement. Stroke recurrence. Embolic stroke of undetermined source. Ischemic stroke.

\section{Resumen}

Objetivos: La patología atrial izquierda es factor de riesgo independiente para infarto cerebral y puede utilizarse para predecir fibrilación auricular. Examinamos si el crecimiento aurícular izquierdo puede predecir recurrencia en pacientes con infarto embolico de origen indeterminado (ESUS). Materiales y métodos: Sesenta y cuatro pacientes con diagnóstico confirmado de ESUS fueron seguidos por una mediana de seguimiento de 22 meses. Registramos los datos clínicos y ecocardiográficos.

Correspondence:

*Antonio Arauz

E-mail: antonio.arauz@p prodigy.net.mx

DOI: 10.24875/ACME.M20000166
Available online: $23-12-2020$

Arch Cardiol Mex. 2020;90(4):461-465 www.archivoscardiologia.com 2604-7063 / @ 2020 Instituto Nacional de Cardiología Ignacio Chávez. Published by Permanyer. This is an open access article under the CC BY-NC-ND license (http://creativecommons.org/licenses/by-nc-nd/4.0/). 
La interpretación ecocardiográfica fue centralizada y cegada. La escala de Brown ESUS - AF fue utilizada para categorizar a los pacientes en riesgo alto (HRP puntaje > 2) y bajo riesgo (no-HRP: puntaje 0-1). El descenlace primario fue recurrencia de infarto cerebral. Resultados: Mediana de edad fue de 62 años (rango: 22-85 años); 33 (51.6\%) fueron hombres. La mediana inicial de la escala de NIHSS fue de 3 putnos (rango de 0 a 27). 12 (18.8\%) pacientes fueron de alto riesgo (HRP) y 52 (81.3\%) de bajo riesgo (non- HRP). El grupo HRP mostró tendencia significatica hacia mayor recurrencia. Tres (25\%) HRP versus 2 (3.8\%) no-HRP experimentaron recurrencia (OR: 8.3 IC 95\% 1.2-57; $p=0.042)$ ); esta asociación se relacionó con dilatación auricular severa (OR: 14.5 IC 95\% 0.78-277, $p=0.02$ ) y edad > 75 años (OR: 12.7 IC 95\% 1.7-92.2, $p=0.03$ ). En el análisis multivarioado, no encontramos significativas. Conclusiones: El crecimiento auricular izquierdo severo y la edad mayor de 75 años mostraron tendencia significativa a recurrencia de infarto cerebral.

Palabras clave: Crecimiento auricular izquierdo. Recurrencia. Embolic stroke of undetermined source. Infarto cerebral.

\section{Introduction}

Cryptogenic stroke accounts for approximately $30 \%$ of all ischemic strokes ${ }^{1}$. Recently, atrial cardiopathy has been shown to be associated with ischemic stroke, particularly those of embolic subtypes ${ }^{2,3}$.

Several studies suggest that not only atrial fibrillation (AF) but also left atrial diameter and other markers of atrial cardiopathy may be implicated in the pathogenesis of cryptogenic stroke ${ }^{4}$. Left atrial enlargement (LAE) has been shown to be associated with incident $A F$ and incident ischemic stroke risk after adjusting for several confounders, including AF. An analysis of NOMASS ${ }^{5}$ showed that moderate to severe LAE is an independent predictor of recurrent stroke risk and is particularly related to embolism (adjusted HR 2.38 95\% Cl 1.03-7.81). Some studies suggest a mechanistic relationship between LAE and ischemic stroke.

Recently, several scores have been proposed to easily and cost-effectively predict paroxysmal AF on outpatient cardiac monitoring after an Embolic Stroke of Undetermined Source (ESUS) $)^{6,7}$. For instance, the Brown ESUS - AF score incorporates moderate - severe $L A E$ and age to assign a score from 0 to 4 with an area under the curve of 0.725 to predict paroxysmal $\mathrm{AF}^{7}$. This score still needs to be externally validated.

We sought to examine LAE and age and its relationship with recurrence and $A F$ development in patients with ESUS using the Brown ESUS - AF score.

\section{Materials and methods}

\section{ESUS cohort}

We analyzed data from 64 patients with confirmed diagnoses of ESUS treated in our hospital from November 2015 to March 2018. We used patient data prospectively included in our stroke database. Our registry includes consecutive outpatients with an acute first-ever confirmed ischemic stroke admitted to the stroke clinic in Mexico City. Every patient in our clinic undergoes a thorough evaluation in search of stroke etiology that comprises brain magnetic resonance imaging (MRI), duplex ultrasound of the neck, transcranial Doppler, and/or computed tomography (CT) angiography of the head and neck arteries, 24-h Holter monitoring, and transthoracic echocardiogram (TE). This study was approved by the local Research and Ethics Committee.

We included patients 18 years old or older with confirmed ischemic stroke by CT or MRI who fulfilled the ESUS criteria ${ }^{8}$. Patients with any identifiable cause of stroke or in whom initial assessments had not been completed were excluded from the study. The diagnosis of ESUS was made according to the ESUS criteria proposed by Hart et al. (1). Ischemic stroke detected by CT or MRI that is not lacunar; (2) absence of extracranial or intracranial atherosclerosis causing $\geq 50 \%$ luminal stenosis in arteries supplying the area of ischemia; (3) no major risk cardioembolic source of embolism and; (4) no other specific cause of stroke identified) ${ }^{8}$. Every patient underwent a comprehensive clinical investigation in search of stroke etiology, including neuroimaging, either $\mathrm{CT}$ or MRI, intracranial and extracranial vessel imaging, TE, and 24-h Holter monitoring.

\section{Echocardiogram}

In all cases, the TE conducted during the index event was evaluated and interpreted by the same certified cardiologist. The left atrial diameter was determined by the auricular area. All measurements were interpreted and recorded on the printed report by the cardiologist using the classification of mild, moderate, or severe LAE according to established parameters ${ }^{9}$.

Patients were categorized into a high (human resource planning [HRP]) or low-risk (non-HRP) group based on their Brown ESUS - AF score (Table 1). Patients were given a score from 0 to 4 according to their 
Table 1. The Brown embolic stroke of undetermined source - atrial fibrillation score

\begin{tabular}{|l|c|}
\hline Variable & Score \\
\hline Age & \\
$-18-64$ years & 0 points \\
$-65-74$ years & +1 points \\
$-\geq 75$ years & +2 points \\
\hline Left atrial enlargement & \\
- Mild & 0 \\
- Moderate - severe & +2 \\
\hline
\end{tabular}

age and LAE. The score is composed of two items. The first is age: patients under 64 years of age score 0 points, patients aged 65-74 years score 1 point, and patients over 75 years old score 2 points. The second variable is LAE: patients with mild LAE score 0 points, and patients with moderate-severe LAE score 2 points. Table 1 shows how the score is composed.

Patients who scored $>2$ were considered HRP. The HRP group was re-evaluated with a new 24-h Holter monitoring in a period of time of 6 months between the first scanning and the second to identify incident AF.

During follow-up, we evaluated stroke recurrence or death. Recurrence was defined as any recurrent stroke occurring during follow-up in any vascular territory, including TIA. Functional outcome was evaluated with the modified ranking scale (mRs); good functional outcome was defined as $m R s>2$.

\section{Statistical analysis}

The statistical analysis was conducted using SPSS (Statistical Package for the Social Sciences, version 23.0, IBM Inc., Armonk, NY). Demographic variables and risk factors for stroke were included in the study. Values for continuous variables were expressed according to their pattern of normality, as evaluated by the Shapiro-Wilk test. Variables that were normally distributed were expressed as the mean and SD, while variables that were not normally distributed were expressed as the median and IQ ranges. Categorical nominal variables were expressed as whole numbers and percentages. Association analysis was performed using Student's t-test or Mann-Whitney Wilcoxon.

A univariate analysis of the independent variables (LAE and age over 65 years) was conducted, with the addition of covariates (sex, hypertension, diabetes, and dyslipidemia), to examine the relationship to appearance of AF and recurrence using a Chi-Square or Fisher's statistic accordingly, respectively. A multivariate regression analysis was performed in search of further associations with respect to the variables of interest.

\section{Results}

We identified 228 consecutive stroke patients in our clinic's database from November 2015 to March 2018. Sixty-four $(28 \%)$ were diagnosed with ESUS. Thirty-three $(51.6 \%)$ were men. The median age was 62 years (range: $22-85$ years). Nineteen patients $(29.7 \%)$ were under 50 years of age. The median initial NIHSS score was 3 points (range: $0-27)$. Forty patients $(77 \%)$ had good clinical outcomes (mRs $\leq 2)$. There was a significant difference in the number of female patients in the HRP group versus non-HRP group. These patients were followed up for a period of time with a median of 20 months (Range of 4-39 months). Table 2 describes the baseline characteristics.

Twelve patients (18.8\%) were categorized as HRP, while 52 (81.3\%) were non-HRP. In the non-HRP group, 34 patients $(53 \%)$ had a Brown ESUS - AF score of 0 , and $18(28 \%)$ had a score of 1 . For the HRP group, seven patients (10.9\%) scored 3 points, $2(3.1 \%)$ scored 2 points, and 3 patients (4.6\%) scored the maximum score of 4 points. Table 3 shows the complete distribution of the scores.

There were two deaths during follow-up in the HRP group versus 0 in the non-HRP $(16.6 \%$ vs. $0 \%$, $p \leq 0.001$ ); one of these deaths was recurrence related, while the other was due to systemic complications of sepsis 18 months after the index event. The remaining ten patients were re-evaluated with a new 24-h Holter monitoring, but we did not document AF in any of these cases.

We found a significant tendency toward recurrence among HRP vs. non-HRP, 3 (25\%) versus 2 (3.8\%) (OR: $8.395 \% \mathrm{Cl} 1.2-57, \mathrm{p}=0.042$ ). A univariate analysis was performed on the variables that could have been associated with recurrence. No significant difference was found for history of arterial hypertension $(p=0.341)$, diabetes mellitus $(p=0.629)$, tobacco use $(p=0.709)$, ischemic heart disease $(p=0.769)$, or hypercholesterolemia $(p=0.454)$. Looking at the variables of interest, age and LAE, only severe atrial enlargement (OR: $14.5 ; 95 \% \mathrm{Cl} 0.78-277, \mathrm{p}=0.02$ ) and age 75 years (OR: $12.7 ; 95 \% \mathrm{Cl} 1.7-92.2, \mathrm{p}=0.03$ ) showed an association with recurrence. A multivariate regression was performed, but no association was found. 
Table 2. Baseline characteristics

\begin{tabular}{|c|c|c|c|c|}
\hline Variable & High-risk $n=12(18.8 \%)$ & Low-risk n = $52(81.3 \%)$ & Total $n=64(100 \%)$ & p value \\
\hline \multicolumn{5}{|l|}{ Demographics } \\
\hline $\begin{array}{l}\text { Age } \\
65 \\
65-74 \\
75\end{array}$ & $\begin{array}{c}1(8.3 \%) \\
2(16.7 \%) \\
9(75 \%)\end{array}$ & $\begin{array}{c}35(65.4 \%) \\
18(34.6 \%) \\
0(0.0 \%)\end{array}$ & $\begin{array}{c}36(54.7 \%) \\
20(31.3 \%) \\
0(14.5 \%)\end{array}$ & $\begin{array}{l}0.001 \\
0.312 \\
0.000\end{array}$ \\
\hline Female & $10(83.3 \%)$ & $21(40.4 \%)$ & $31(48 \%)$ & 0.007 \\
\hline $\begin{array}{l}\text { Clinical } \\
\text { HTN } \\
\text { Diabetes Mellitus } \\
\text { Tobacco } \\
\text { Dyslipidemia } \\
\text { Cardiopathy }\end{array}$ & $\begin{array}{c}9(75 \%) \\
2(16.7 \%) \\
2(16.7 \%) \\
1(8.3 \%) \\
1(8.3 \%)\end{array}$ & $\begin{array}{c}32(61.5 \%) \\
17(33.3 \%) \\
18(34.6 \%) \\
5(9.6 \%) \\
0(0.0 \%)\end{array}$ & $\begin{array}{c}41(64.1 \%) \\
19(30.2 \%) \\
20(31.3 \%) \\
6(9.4 \%) \\
1(1.6 \%)\end{array}$ & $\begin{array}{l}0.357 \\
0.258 \\
0.427 \\
0.891 \\
0.628\end{array}$ \\
\hline $\begin{array}{l}\text { Clinical course } \\
\text { NIHSS (range) } \\
\text { mRs } 2 \text { discharge } \\
\text { mRs 2-3 months } \\
\text { mRs 2-6 months }\end{array}$ & $\begin{array}{c}2.5(0-18) \\
11(91.4 \%) \\
11(91.4 \%) \\
11(91.4 \%)\end{array}$ & $\begin{array}{c}3.5(0-27) \\
41(78.4 \%) \\
41(78.4 \%) \\
4379.6 \%)\end{array}$ & $\begin{array}{l}52(82.5 \%) \\
52(82.5 \%) \\
54(85.7 \%)\end{array}$ & $\begin{array}{l}0.464 \\
0.355 \\
0.355 \\
0.513\end{array}$ \\
\hline
\end{tabular}

HTN: hypertension; NIHSS: National Institutes of Health Stroke Scale; mRs: modified rankin scale.

Table 3. Left atrial enlargement, age, and corresponding brown embolic stroke of undetermined source - atrial fibrillation score

\begin{tabular}{|l|c|c|}
\hline Variable & $\mathbf{n}(\%)$ & Brown score \\
\hline Left atrial enlargement & & \\
$\quad$ Absent & $46(72)$ & +0 \\
Mild & $12(19)$ & +0 \\
Moderate & $4(6)$ & +2 \\
$\quad$ Severe & $2(3)$ & +2 \\
\hline Age (years) & & \\
65 & $35(54)$ & +0 \\
$65-74$ & $20(31)$ & +1 \\
75 & $9(14)$ & +2 \\
\hline
\end{tabular}

\section{Discussion}

Patients with ESUS represent a heterogeneous group with a high probability of their stroke having a cardiac embolic source and a higher risk of stroke recurrence $^{3,10}$. In a recent population-based study, LAE has been shown to be associated with incident $A F$ and incident ischemic stroke ${ }^{5,11}$. Our findings reinforce the argument that LAE should be considered a risk factor for recurrent ischemic stroke and suggest that left atrial thromboembolism can occur independently of documentation of $\mathrm{AF}^{12}$.

The baseline characteristics of our cohort are compatible with those reported in the literature; ESUS patients tend to be younger and have less severe strokes $^{3,13,14}$. Nevertheless, we observed that women are at higher risk (OR: $7.395 \% \mathrm{Cl} 1.4-37.1, \mathrm{p}=0.007$ ), a finding that correlates with other prognostic scales such as $\mathrm{CHA}_{2} \mathrm{DS}_{2}$-VASC, in which female sex confers risk of recurrence ${ }^{15}$.

A significant tendency was found between HRP and stroke recurrence compared with non-HRP (OR: 8.3 $95 \% \mathrm{Cl} 1.2-57, p=0.042)$; this relationship was conditioned by age $>75$ years and severe atrial dilation as demonstrated in the univariate analysis. Although our patients may have presented subclinical AF, the important aspect of our findings is that the risk of recurrence can be predicted with documentation of LAE on a conventional echo. Therefore, we did not find a relation between LAE, age, and AF development, which can be readily explained by our AF monitoring strategy, which was only a 24-h Holter monitor, known to have a low diagnostic yield for paroxysmal $A F^{2}$. Subclinical $A F$ is suggested to play an important role in ESUS pathogenesis, and proper screening for $\mathrm{AF}$ in these patients is mandatory ${ }^{16}$. Unfortunately, the reality for most countries in Latin America is that prolonged monitoring, external, or implantable, is very scarce, so searching for better strategies to further select patients who would benefit the most from more strict follow-up protocols is essential. Patients with LAE have been shown to have reduced left atrial contractility, leading to reductions in left atrial volume and kinetic energy. The resultant dysfunctional left atrium leads to atrial thromboembolism. 
Furthermore, LAE can promote stasis, endothelial dysfunction, and thrombus formation ${ }^{17}$. In addition, patients with LAE are more likely to have well-known stroke risk factors, which possibly increased their risk of developing stroke.

Our findings suggest that the detection of LAE in patients with ESUS allows the identification of patients at high risk of recurrence in which some pharmacological therapies could be beneficial. In a subanalysis of ESUS NAVIGATE patients with ESUS and enlarged left atrium, there was a lower recurrence rate in the rivaroxaban group, though these results must be taken with caution since they are a positive subgroup in an overall negative trial; however, they show some promising evidence that better-selected ESUS patients may indeed benefit from anticoagulants ${ }^{18}$.

This study was not intended to function as an external validation for the Brown Score since we do not have the option at our center to place our patients on prolonged cardiac monitoring. The score is simple to apply, and it does not require any additional evaluation beyond the standard etiology screening. Better strategies for AF detection that is both feasible and cost effective need to be structured for this group of patients. LAE could be a valuable biomarker to select patients with high risk of stroke recurrence, and further studies need to be performed to fully assess this suggestion. Some limitations of our study must be recognized. First, the small number of patients included is a limitation, considering that this is a selected group of patients with specific ESUS criteria in which no other probable cause of IC was demonstrated. A second limitation is that our sample came from a single neurological center.

\section{Conclusion}

Our findings suggest that patients with severe LAE who are 75 years old or older have a significant tendency to experience stroke recurrence.

\section{Conflicts of interest}

The investigators of this study confirm that there are no conflicts of interest to disclose.

\section{Funding}

All the expenses generated in this study were financed by the research fund of the Stroke Clinic of the National Institute of Neurology and Neurosurgery Manuel Velasco
Suaárez which is a fund private, independent, and governed by the regulations of the same institute.

\section{Ethical disclosures}

Protection of human and animal subjects. The authors declare that no experiments were performed on humans or animals for this study.

Confidentiality of data. The authors declare that they have followed the protocols of their work center on the publication of patient data.

Right to privacy and informed consent. The authors declare that no patient data appear in this article.

\section{References}

1. Saver JL. Cryptogenic stroke. N Engl J Med. 2016;374:2065-74

2. Sanna T, Diener HC, Passman RS, Di Lazzaro V, Bernstein RA, Morillo $\mathrm{CA}$, et al. Cryptogenic stroke and underlying atrial fibrillation. $\mathrm{N}$ Engl J Med. 2014;370:2478-86.

3. Hart RG, Catanese L, Perera KS, Ntaios G, Connolly SJ. Embolic stroke of undetermined source: a systematic review and clinical update. Stroke. 2017:48:867-72.

4. Sebasigari D, Merkler A, Guo Y, Gialdini G, Kummer B, Hemendinger M, et al. Biomarkers of atrial cardiopathy and atrial fibrillation detection on mobile outpatient continuous telemetry after embolic stroke of undetermined source. J Stroke Cerebrovasc Dis. 2017;26:1249-53.

5. Yaghi S, Moon YP, Mora-Mclaughlin C, Willey JZ, Cheung K, Di Tullio R, et al. The Northern Manhattan Stroke Study. Stroke. 2015. p. 1488-93.

6. Grond M, Toenges G. Development and validation of a score to detect paroxysmal atrial fibrillation after stroke. Neurology. 2019;92:e115-24.

7. Ricci B, Chang AD, Hemendinger M, Dakay K, Cutting S, Burton T, et al. A simple score that predicts paroxysmal atrial fibrillation on outpatient cardiac monitoring after embolic stroke of unknown source. J Stroke Cerebrovasc Dis. 2018;27:1692-6.

8. Hart RG, Diener HC, Coutts SB, Easton JD, Granger CB, O'Donnell MJ, et al. embolic strokes of undetermined source: the case for a new clinical construct. Lancet Neurol. 2014;13:429-38.

9. Lang RM, Badano LP, Mor-Avi V, Afilalo J, Armstrong A, Ernande L, et al. Recommendations for cardiac chamber quantification by echocardiography in adults : an update from the American society of echocardiography and the European association of cardiovascular imaging. J Am Soc Echocardiogr. 2015;28:1-39.e14.

10. Ntaios G, Vemmos K, Lip GY, Koroboki E, Manios E, Vemmou A, et al Risk stratification for recurrence and mortality in embolic stroke of undetermined source. Stroke. 2016;47:2278-85.

11. Woz B. Changes in left atrial size in patients with persistent atrial fibrillation: a prospective echocardiographic study with a 5-year follow-up period. Int J Cardiol. 2005;101:47-52.

12. Yaghi S, Kamel H, Elkind MS. Atrial cardiopathy: a mechanism of cryptogenic stroke. Expert Rev Cardiovasc Ther. 2017;15:591-9.

13. Diener HC, Bernstein R, Hart R. Secondary stroke prevention in cryptogenic stroke and embolic stroke of undetermined source (ESUS). Curr Neurol Neurosci Rep. 2017;17:17-21.

14. Arauz A, Morelos E, Colín J, Roldán J, Barboza MA. Comparison of functional outcome and stroke recurrence in patients with embolic stroke of undetermined source (ESUS) vs. Cardioembolic stroke patients. PLoS One. 2016;11:1-9.

15. Lip GY, Nieuwlaat R, Pisters R, Lane DA, Crijns HJ. Refining clinical risk stratification for predicting stroke and thromboembolism in atrial fibrillation using a novel risk factor-based approach: the Euro heart survey on atrial fibrillation. Chest. 2010;137:263-72.

16. Tomita H, Sasaki S, Hagii J, Metoki N. Covert atrial fibrillation and atrial high-rate episodes as a potential cause of embolic strokes of undetermined source: their detection and possible management strategy. J Cardiol. 2018;72:1-9.

17. Goyal SB, Spodick DH, Worcester F. Electromechanical dysfunction of the left atrium associated with interatrial block. Am Heart J. 2001;142:823-7.

18. Healey JS, Gladstone DJ, Swaminathan B, Eckstein J, Mundl H, Epstein $A E$, et al. Recurrent stroke with rivaroxaban compared with aspirin according to predictors of atrial fibrillation secondary analysis of the NAVIGATE ESUS randomized clinical trial. JAMA Neurol. 2019;76:764-73 